\title{
Ectopic calcification around joints of paralysed limbs in hemiplegia, diffuse brain damage, and other neurological diseases $^{*}$
}

\author{
ARNOLD J. ROSIN \\ From Harzfeld Hospital, Gedera, Israel
}

\begin{abstract}
Rosin, A. J., (1975). Annals of the Rheumatic Diseases, 34, 499-505. Ectopic calcification around joints of paralysed limbs in hemiplegia, diffuse brain damage, and other neurological diseases. Mechanical deformity associated, with neurological disease is commonly encountered in the form of contractures, or pre-existing arthritis. Less common is the occurrence of ectopic calcification around the joints of a paralysed limb. Two forms of this are presented in a series of twenty patients. Para-articular calcification with the appearance of myositis ossificans around large joints of the affected limbs occurred most often. The interior of the joints was not affected, nor was there evidence of bony injury. In some cases, however, the excessive outgrowth of bone around the joint eventually resulted in a functional ankylosis by a uniting bar of bone outside the joint. The second form of calcification was periosteal, which unlike the first type was resorbed and left an area of cortical bony thickening.

The twenty patients with para-articular calcification included ten with hemiplegia due to cerebrovascular accidents, two with paraplegia due to trauma, one case of cauda equina syndrome, and seven cases of head injury with periods of unconsciousness ranging from weeks to months. The hip and shoulder joints were most commonly affected, but elbows and knees were sometimes involved. In two cases fractures showed excessive callus formation. In no case was ectopic calcification seen elsewhere in the body.

Calcification developed within weeks to months of the initial stroke or injury. The degree of neurological deficit was usually severe. Radiation treatment was given in two cases for pain, but the process of calcification and ossification was complete within a period of months, and in another case pain remitted spontaneously. Surgery was carried out in one patient when the ossifying process had stopped in order to correct deformity for the sake of functional improvement of the limb.
\end{abstract}

Theories of causation and indications for treatment are discussed.

The deposition of ossified bone round the joints of limbs in patients with neurological disease has been described over the past 50 years. Soule (1945) reported para-articular calcification round the hips of warinjured paraplegics, and pointed out the severity of the neurological deficit, and that some cases were associated with infection. Damanski (1961), in reviewing the subject, mentioned the frequency of the phenomenon in association with spastic paraplegia from lower dorsal injuries. Isolated cases were described in hemiplegia due to cerebrovascular accident by Voss (1937), Irving and LeBrun (1954),
Roberts (1968), Radt (1970), and Rosin (1970). Other conditions mentioned in published reports in which para-articular calcification occurs are multiple sclerosis, encephalitis, and cerebral tumour (Storey and Tegner, 1955). Recently, calcification occurring around joints in patients suffering unconsciousness and neurological damage as a result of head injury has been reported (Roberts, 1968; Pryor, 1970; Money, 1972).

The phenomenon consists of ectopic calcification within the muscles around large joints of affected limbs, without involvement of the interior of the joint 
itself. The calcifying process proceeds to ossification, ranging from a large mass of bone surrounding the joint and even uniting with adjoining bony structures to discrete knots of bone in the muscular tissues near the joint. Another type of calcifying process occasionally described is that of subperiosteal calcification with subsequent regression of the process, leaving a residual thickening of the bony cortex in the subarticular zone.

Details of twenty patients with neurological deficits from different causes in whom para-articular calcification appeared around one or more joints are presented. An attempt was made to find a correlation between specific neurological features and the development of calcification. The cases were 10 hemiplegics due to cerebrovascular accidents; 2 paraplegics due to injury to the dorsal spine; 1 case of cauda equina lesion due to prolapsed disc and following laminectomy; 7 cases of head injury with prolonged periods of unconsciousness. Most were seen in Harzfeld Hospital over the past 5 years; two of the hemiplegic patients were described in detail in a previous publication (Rosin, 1970).

\section{The Series}

\section{HEMIPLEGIC PATIENTS}

The clinical features of the 10 hemiplegic patients were characterized by a relatively advanced age (60-83 years, mean 72), severe neurological deficit, spastic limbs, and more or less severe sensory loss. All except two complained of pain, and this emphasized the inclusion of ectopic calcification as a cause of pain associated with hemiplegia. For example, the cause of pain in the upper thigh was not apparent in one of the patients until 4 weeks after the stroke when the first signs of calcification appeared around the hip joint. Figs 1 and 2 show the development in another patient of calcification from 4 weeks to 4 months after the onset of the stroke. In this case the diagnosis was

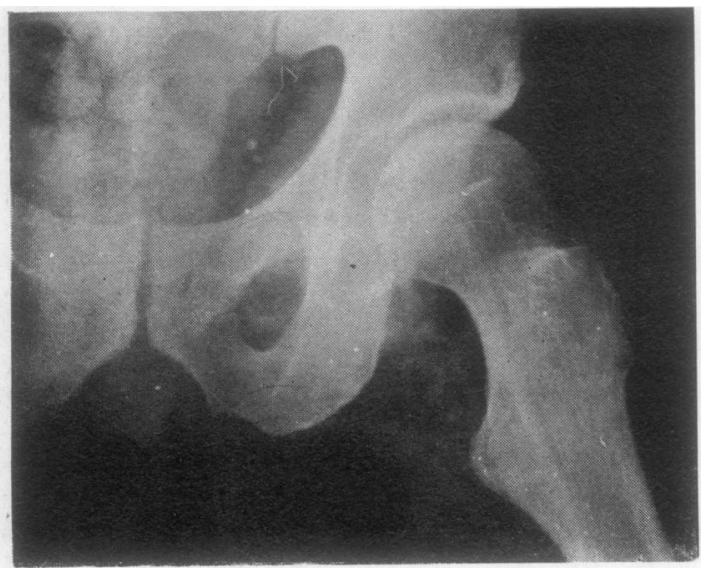

FIG. 1 Onset of calcification round the right hip of a patient 1 month after right hemiplegia

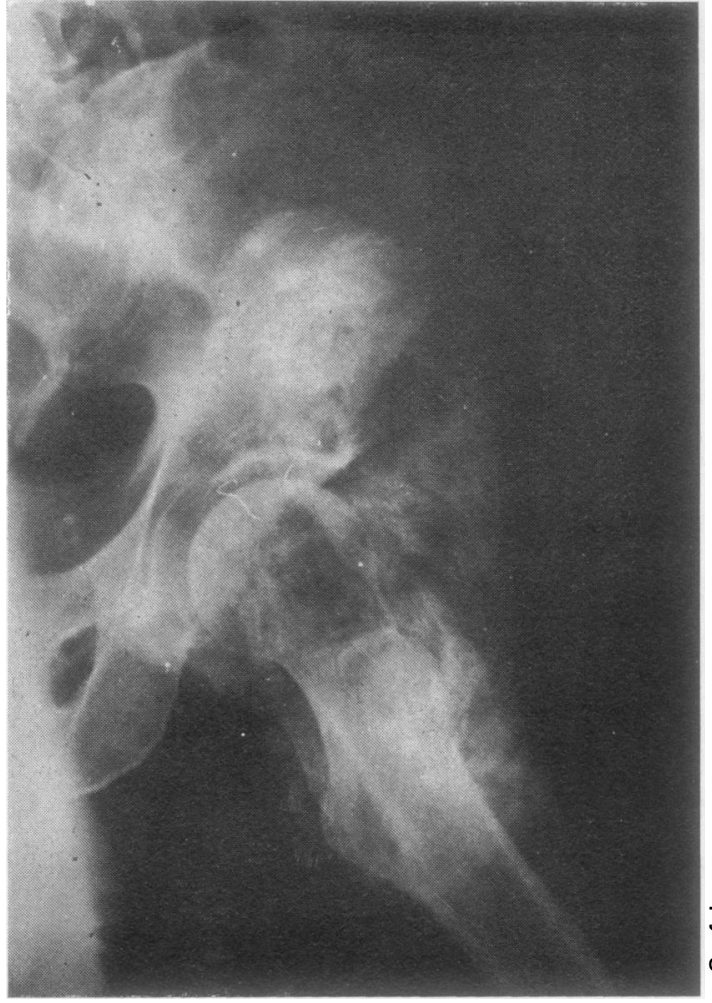

FIG. 2 Hip of patient shown in Fig. 1, 4 months after hemiplegia, showing increase in density and extent of calcification

made clinically by the externally rotated hip and palpation of a hard mass overlying the groin. This patient, who had a severe hemianaesthetic syndrome, also exhibited calcification round the shoulder joint, which was painful and resembled the picture of a 'frozen' shoulder (Fig. 3).

Deep $x$-ray therapy was given to two patients with pain around the hip owing to the ossifying mass, and the pain remitted within 6-8 weeks. In the other untreated cases it lessened in following months, with some residual discomfort.

The presence of calcification around the joints might occur in grossly rigid limbs, and might therefore not be suspected. A woman of 65 presented with rigidity of all 4 limbs. She had suffered a left hemiparesis 6 months previously, and 2 months before admission to Harzfeld Hospital she suddenly became unconscious for some days, with fever and raised blood urea. She recovered consciousness, but remained in bed and acquired pressure sores. She lay in a flexed position, with gross limitation of passive hip movements. Active movements of her hands were possible against mild resistance, but were limited by contractures of elbows and shoulders, especially on the left. She was alert and orientated. $X$-ray showed gross calcified masses around both hips and above the right shoulder joint.

Of interest were the two patients with fractures of the femur. One fractured the neck of the femur at the time of a 
stroke when he fell out of bed, and the other the upper shaft one month after the onset of hemiplegia. On palpation a gross mass of callus could be felt, the extent of which was unaltered several months later (Fig. 4). The

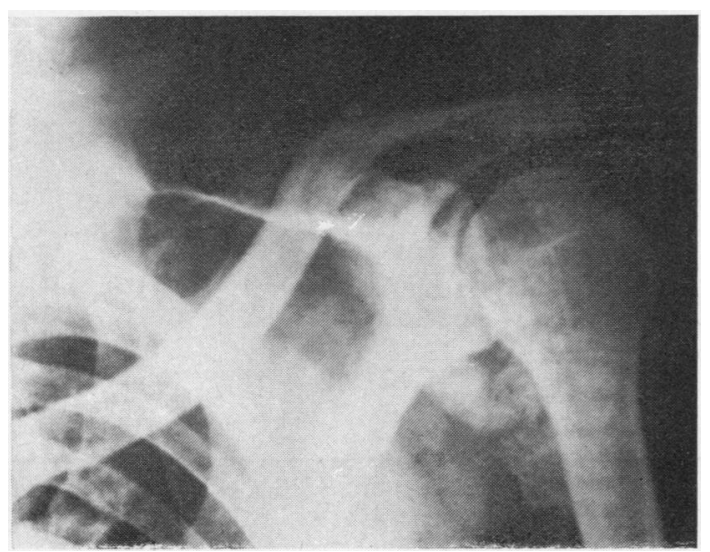

FIG. 3 Right shoulder of patient shown in Figs 1 and 2

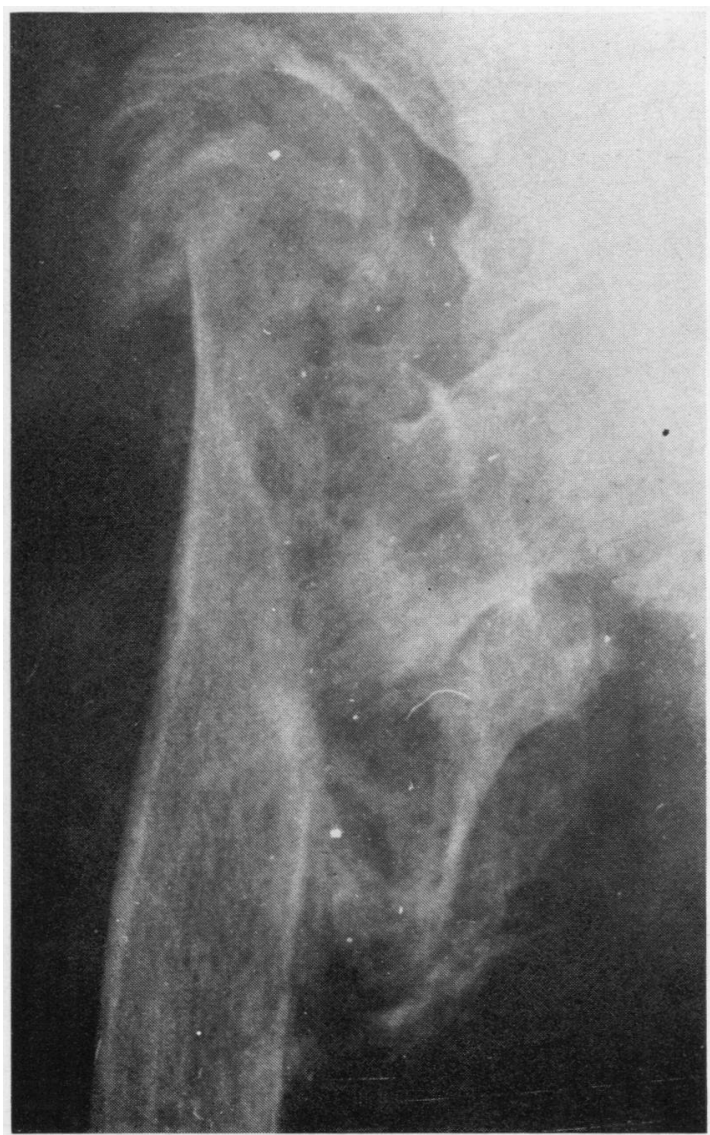

FIG. 4 Right hip of patient 6 weeks after fracture of the neck of femur simultaneous with right hemiplegia, showing excessive callus formation union of the pertrochanteric fracture resulted in a virtual ankylosis by the mass of bone outside the joint uniting with the pelvis.

Despite the severity of the neurological lesion three patients regained the ability to walk. Comparison of hemiplegic patients without para-articular calcification revealed no differences regarding side of hemiplegia, incidence of unconsciousness at the outset, or sensory signs. Moreover, fracture of the femur at the time of the onset of a hemiplegia or shortly thereafter is not uncommon, but is not usually associated with excessive callus to the extent of myositis ossificans.

\section{PARAPLEGIC PATIENTS}

The two cases included in the series differ little from those described in other articles and reviewed extensively by Hardy and Dickson (1963) and Guttman (1973). Both had a sensory level at D6 and D9, respectively. Both had para-articular calcifications around both hips. One acquired a stress fracture of the upper shaft of the femur while manually exercising it, and at the site of the fracture there was an excessive outgrowth of callus which did not regress in amount over the next 5 years. We have not encountered para-articular calcification in paraplegia resulting from motor neurone disease.

\section{SPINAL CORD LESION}

A woman of 70, of Turkish origin, presented with pain and weakness in the left leg, and was found to have a lower motor neurone and sensory deficit consistent with root pressure. A laminectomy was performed after a myelogram was taken which indicated pressure from a prolapsed disc at L3,4, but the weakness was no better and the hypoaesthesia was complicated by indolent sacral pressure sores. A year later she was barely able to walk with a Zimmer frame, and began to complain of pain in the right buttock radiating down the thigh. The objective neurological picture had not changed and $x$-ray of the pelvis showed calcification between ischium and the lesser trochanter. The pain began to subside after several months. Estimations of the serum alkaline phosphatase during this time showed a rise from 3.7 Bodansky units to $5 \cdot 6$ (normal $4 \cdot 5$ ) and back to $4 \cdot 7$.

\section{HEAD INJURY}

Fifteen cases have been encountered of head injury or cerebral anoxia resulting in diffuse brain damage and periods of unconsciousness ranging from 3 weeks to 4 years. In six of these patients there were clear radiological signs of calcification around several joints (Table I). In one further case of quadriplegia who was in an unresponsive state (Jennett and Plum, 1972) for 2 years after cardiac arrest from $\mathrm{CO}_{2}$ poisoning, flecks of clacification appeared above and below the trochanters of both femora. In another case, not included in the series, who recovered consciousness after several weeks, it was not clear subsequently whether or not the calcified masses posterior to the knee joint were connected with a fracture of the tibia. Table I compares the six patients with definite periarticular calcification with seven patients in whom calcific masses did not appear. The state of consciousness in each group was comparable, varying from deep un- 
Table I Comparison of patients with prolonged unconsciousness who did not develop para-articular calcification

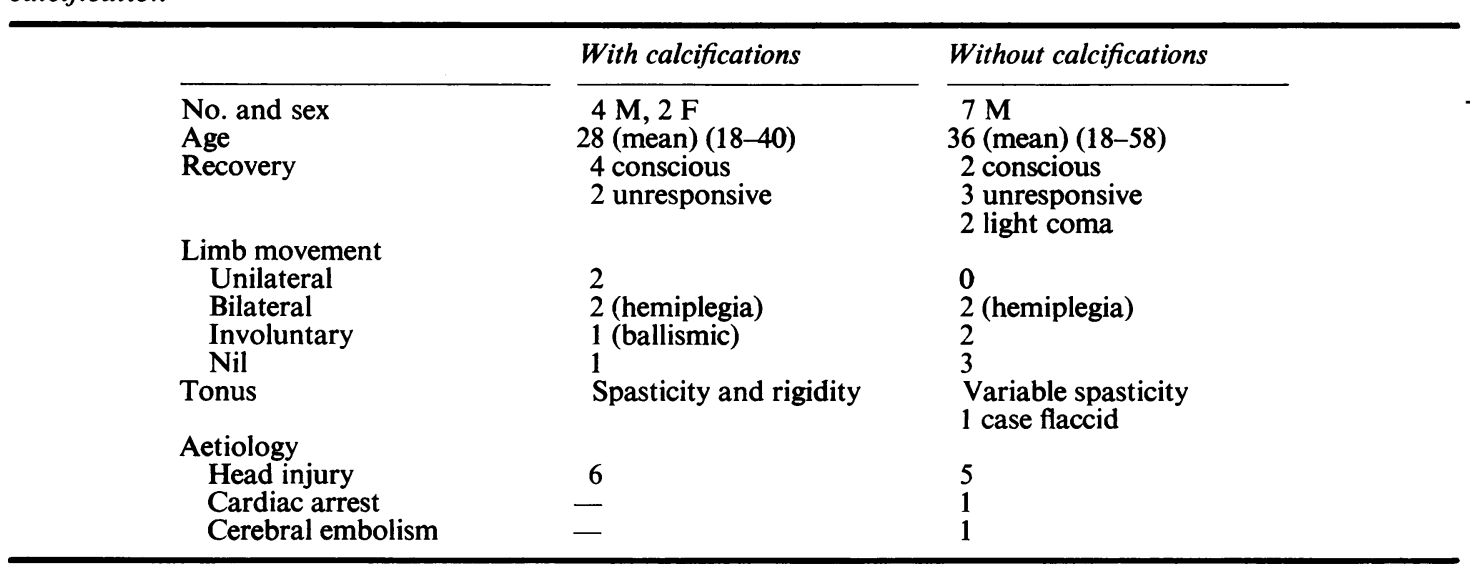

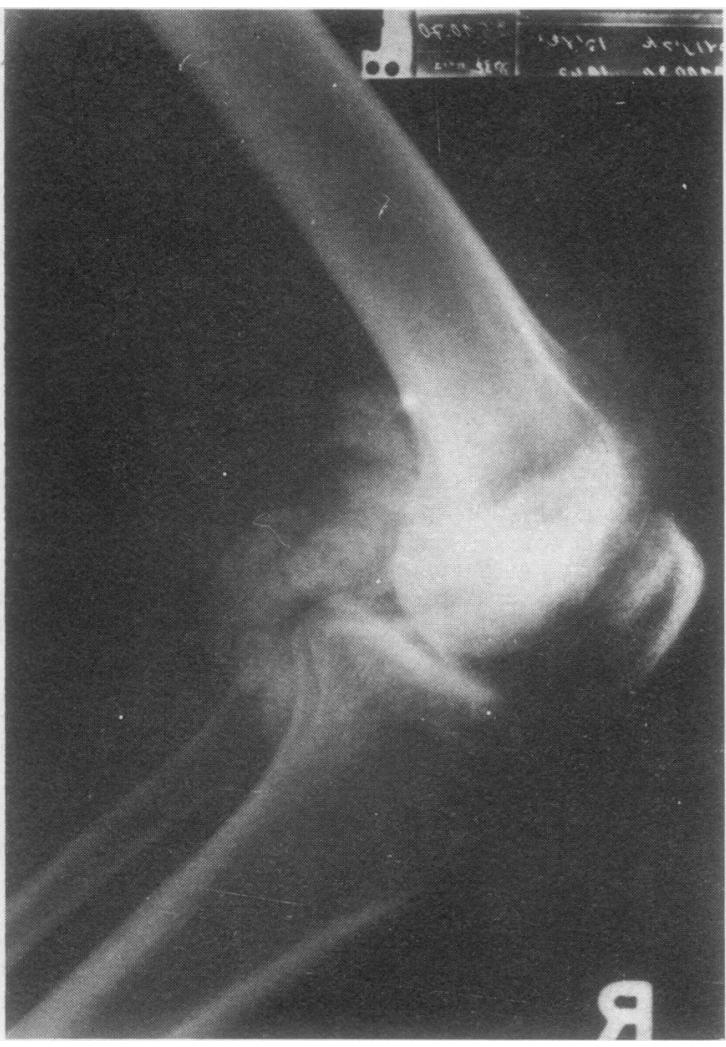

FIG. 5 Knee of patient 4 months after head injury which resulted in unconsciousness for 1 month. Para-articular calcification caused severe flexion deformity, and the bony masses were removed surgically

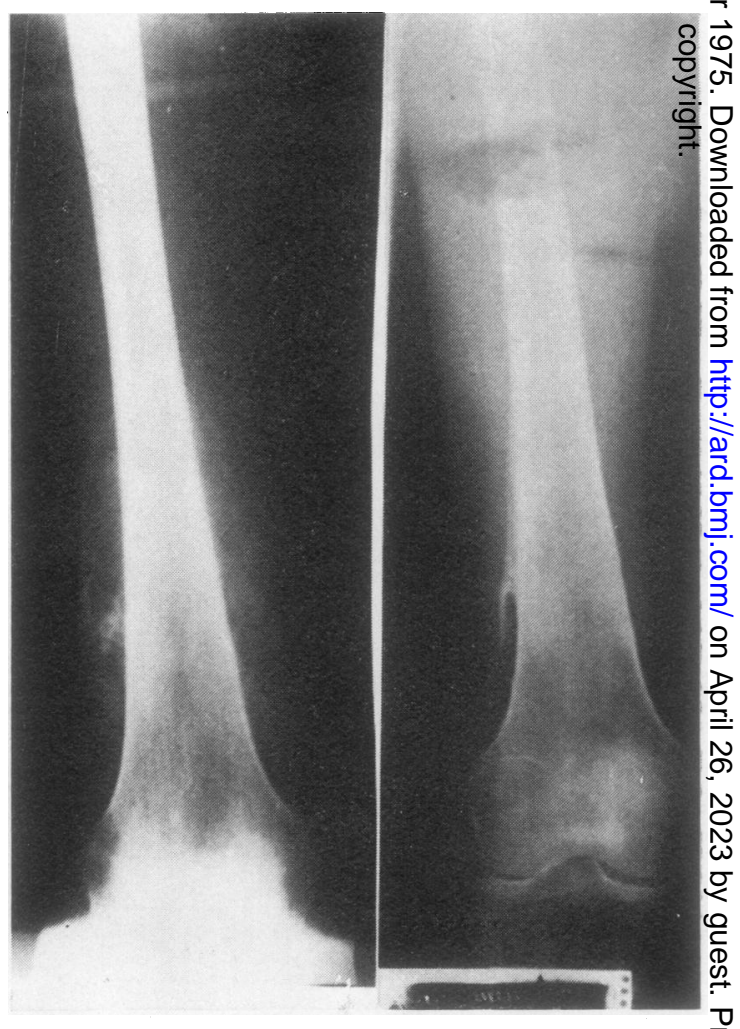

FIG. 6 Lower end of the femur 3 months and 15 month. after severe head injury resulting in coma for 3 months Subperiosteal calcification was noted and later almos $\overrightarrow{1}$ completèly disappeared 


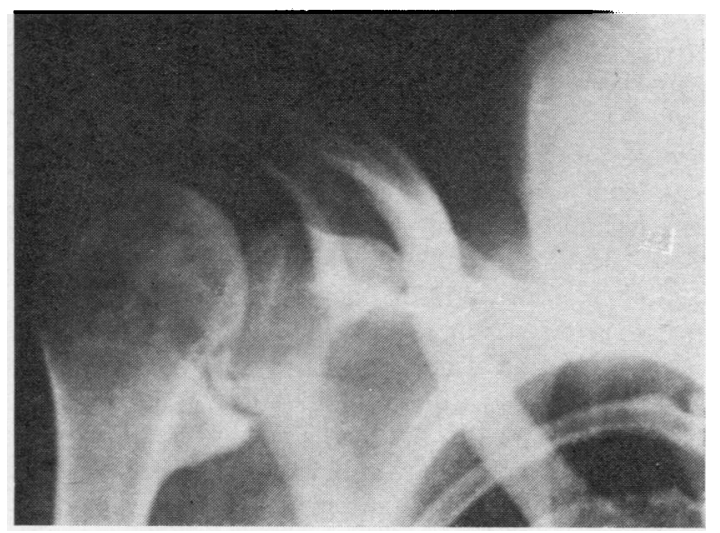

FIG. 7 Periosteal outgrowth from subarticular portion of the humerus 5 years after head injury with residual quadripare $i c$ damage

consciousness with response to noise alone, to a state of 'prolonged unresponsiveness' (Jennett, and Plum, 1972), and varying degrees of light coma. The diagnosis was made by palpating the characteristic hard swellings around joints, and was confirmed by $x$-ray.

A man of 23 sustained a head injury when he fell from a second floor window. When examined 6 weeks later he responded to painful stimuli, was aphasic, had a spastic right hemiplegia and rigidity of the left limbs. The limbs were held in flexion spasm, and hard swellings round the hips and shoulders were noted. He recovered consciousness, and within the next 2 months his speech improved and movement returned to the left side. The mechanical deformity caused by the para-articular calcification prevented standing or walking (Fig. 5). Surgery was carried out to remove the blocks of bone round the knees. Although the hips retained a degree of permanent flexion, he became able to walk, ride a bicycle, and travelled to a rehabilitation centre in Tel-Aviv.

A combination of para-articular calcification and excess subperiosteal deposition of bone was seen 3 months after a head injury from a motor accident in an 18-year-old girl. She was in a state of decerebrate rigidity, in light coma, and palpation of the lower end of the femora gave the impression that they had been fractured. $X$-ray showed this not to be so and follow-up 1 year later showed almost complete resorption with a residual spur of bone (Fig. 6). The ectopic calcifications round the elbows and shoulder did not regress at all, and constituted a mechanical block to movement.
Fig. 7 shows the shoulder of a 20-year-old girl 5 years after she sustained a severe head injury with a partially recoverable quadriplegia. The outgrowth of cortex (which was also present in the other humerus) probably represents the residue of subperiosteal calcification which occurred at the time of the head injury.

Table II summarizes the sites at which para-articular calcification was seen in all the cases. In some of the head injury patients, it occurred on both sides, but not necessarily in the corresponding joints.

\section{Discussion}

The para-articular calcification described in the above cases occurred around the joint and was sometimes so extensive as to resemble myositis ossificans. Two positive symptoms and two negative ones were apparent. There was pain in most cases of hemiplegia associated with the growth and development of the calcification. The paraplegic patients with sensory loss did not, however, feel pain, nor did patients with head injury who developed the calcification while in a state of impaired consciousness. The other important symptom was mechanical loss of movement at the joint due to ankylosis from around it. This might result in difficulty in sitting because of only minimal flexion position of the hips, or inability to stand because of fixation of kness or hips in flexion, both of which complications were seen among the above patients.

A feature which is lacking in this syndrome of heterotopic calcification is involvement or destruction of the joint itself, as, for example, occurs in Charcot joints associated with sensory nerve disturbances. Furthermore, apart from ectopic calcification near joints of limbs involved in the neurological deficit, calcium is not laid down in soft tissues elsewhere, and this differentiates the condition from myositis ossificans progressiva, or calcinosis universalis.

In the present series one case of subperiosteal calcification was seen which differed from the paraarticular form in that it regressed and after a year only a spur of bone remained protruding from the cortex. In one other patient a similar subarticular periosteal thickening was seen in $x$-ray of both upper humeri 5 years after head injury and prolonged unconsciousness. In all other cases the mass of calcification

Table II Sites of para-articular calcification in the 20 patients

Sites of calcification

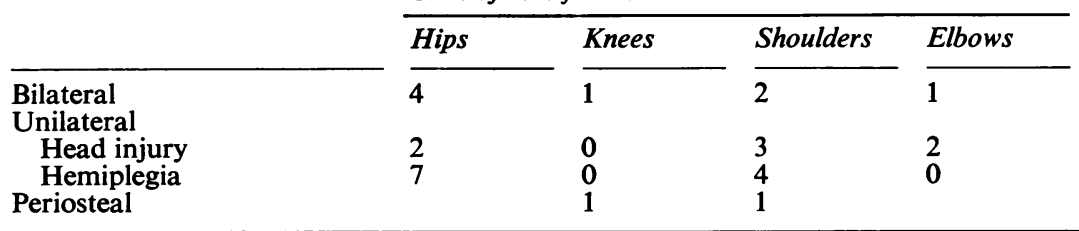


appeared to grow to a certain extent, then became more calcified and ossified, but did not regress.

Treatment is directed towards relieving pain and correcting mechanical contracture where this is functionally inconvenient. Since this is a vascular growing tissue during the ossifying stage, attempts to remove it surgically fail because of gross bleeding and regrowth of the bone (Radt, 1970). Deep $x$-ray therapy was tried (Furman, Nicholas, and Jivoff, 1970; Rosin, 1970), and the pain remitted after a few weeks, but in some other cases it subsided spontaneously after several weeks. Russell, Smith, Bishop, Price, and Squire (1972) used a diphosphonate compound in the treatment of systemic myositis ossificans because of its property to inhibit the crystallization of hydroxyapatite, and succeeded in arresting the disease. A trial of this substance during the developing phase of the ossified mass in brain injury or vascular disease would be worth while.

Surgery is indicated after the completion of ossification, from 6 months after onset when the removal of hard bone may not necessarily be followed by bleeding or by recalcifications. This was achieved in one of the postcranial injury cases with a good functional result in movement of the lower limbs and walking.

The cause of the condition remains a mystery. Although we have seen it only in elderly hemiplegics, it was reported in two patients with strokes under the age of 50 by Roberts (1968). Age had no influence on the appearance of periarticular ossification in the patients with paraplegia or head injury. The neurological lesion caused spasticity in most cases and one case of prolonged and deep unconsciousness with flaccid limbs 4 years after the brain injury had no evidence of the calcified lesions. However, spasticity was not an invariable finding, and the degree of increase of muscle tone bore no relation to the disposition of the periarticular calcification. No relation was found between the occurrence of calcification around joints and the incidence of unconsciousness at the onset of the stroke, the degree of neurological or functional recovery, or the degree of sensory impairment.

The relationship of a rising alkaline phosphatase with the development of the bony mass (Nechwatel,
1973; Furman, and others, 1970) is a reflection of active bone formation and may be used as an indication that ectopic calcification is proceeding despite the absence of symptoms. The occurrence in three of our cases of excessive callus around fractures points to an exaggerated response to proliferation of repair bony tissue. However, this does not happen in every case of fracture in a hemiplegic limb. Moreover, the possibility of a traumatic haematoma seems unlikely since no predisposing feature rendering the limb more liable to traction was seen in those cases compared with hemiplegics without calcification. We have seen no case with myositis ossificans around a subluxated shoulder of a hemiplegic limb, in which rupture of the supraspinatus is said to take place (Chaco and Wolf, 1971). Although severe infection near the area of calcification has been suggested as an aetiological factor, many of our patients had no infection and many para-articular calcifying masses were remote from pressure sores. One of the early descriptions of 'atypical myositis ossificans' (Johnson, 1957) concerned cases of burns in which calcification occurred around joints which were immobilized either because of the burn or because of the treatment. In most cases the ossifications occurred around joints remote from the burnt site. This common factor of immobilization of the limb also appears in the cases quoted above What is strange is that ossification does not occub more often in hemiplegia, that neurological recover with limb movement took place in some cases, and that ossification was seen around some joints and not others after severe head and brain injury.

Another theory suggested is that sympathetic dysfunction causes changes in vascularization to the periarticular tissues, with osteoporosis of the bone and transfer of calcium to the tissues outside the joint (Lippman, 1960). The rapid and firm union of the fractures in the cases with the excessive callus does not favour this, but instead supports the idea of change in mesenchymal cell function from that of making connective tissue to that of making bone. How this stimulus is caused by the disturbance of neurological function is not known, but the result seems to be a rapid localized vascularization near the joint with ossification in the connective tissue and muscle.

\section{References}

Chaco, J., ANd Wolf, E. (1971) Amer. J. Phys. Med., 50, 139 (Subluxation of the gleno-humeral joint in hemiplegia)

Damanski, M. J. (1961) J. Bone Jt Surg., 43B, 286 (Heterotopic calcification in paraplegia)

Furman, R., Nicholas, J. J., AND Jivoff L. (1970) Ibid., 52A, 1131 (Elevation of the serum alkaline phosphatase co-incident with ectopic bone formation in paraplegic patients)

Guttman, L. (1973) In 'Spinal Cord Injuries'. Blackwell, London

Hardy, A. G., ANd Dickson, J. W. (1963) J. Bone Jt Surg., 45B, 76 (Pathological ossification in traumatic paraplegia)

IRving, J., AND Le BRUN, H. (1954) Ibid, 36B 440 (Myositis ossificans in hemiplegia) 
JoHnson, J. T. H. (1957) J. Bone Jt Surg., 39A, 189 (Atypical myositis ossification)

JeNnetr, B., AND Plum, F. (1972) Lancet 1, 734 (Persistent vegetative state after brain damage. A syndrome in search of a name)

Lippman, M. (1960) Arch. phys. Med., 41, 351 (Heterotopic calcification-a problem in rehabilitation medicine)

MoNEY, R. (1972) Med.J. Aust., 1, 125 (Ectopic para-articular ossification after head injury)

Nechwatal, E. (1973) Paraplegia, 11, 79 (Early recognition of heterotopic calcification by means of alkaline phosphatase).

PRYOR, J. P. (1970) J. Neurosurg., 32353 (Dystrophic muscle calcification following cerebral damage)

RADT, P. (1970) Geriatrics, 25, 142 (Peri-articular ectopic ossification in hemiplegics)

ROBERTS, P. H. (1968) J. Bone Jt Surg., 50B, 70 (Heterotopic ossification complicating paralysis of intracranial origin)

Rosin, A. J. (1970) J. Amer. Geriat. Soc., 18, 916 (Periarticular calcification in a hemiplegic limb).

Russell, R. G. G., SMith, R., Bishop, M. C., PRICE, D. A., AND SQUiRe, C. M. (1972) Lancet, 1, 10 (Treatment of myositis ossificans progressive with a diphosphonate)

SoulE, A. B. (1945) J. Neurosurg, 2, 485 (Neurogenic ossifying fibromyopathies)

STOREY, G., AND TEGNER, W. S. (1955) Ann. rheum. Dis. 14, 176 (Paraplegic para-articular calcification)

Voss, H. (1937) Fortschr. Röntgenstr., 55, 423 (Uber die parostalen und para-artikulären Kuschen neubildungen bei organischen Nervenkrankleiten) 